\title{
A Study of factors contributing towards the effectiveness of E-recruitment among generation $Y$ job seekers
}

\author{
Jayanty Kuppusamy*, Jaya Ganesan \\ Faculty of Business, Multimedia University, Malacca, Malaysia
}

\section{A RT ICLE INFO}

\section{Article history:}

Received 18 September 2016

Received in revised form

27 November 2016

Accepted 16 December 2016

\section{Keywords:}

E-recruitment

Internet

Information

Website

\begin{abstract}
A B S T R A C T
E-recruitment is widely used by individuals and organizations as the main mode for recruitment. Its growth is attributed to the advancement in Internet technology. Therefore, this study focuses on identifying the factors that contribute towards the effectiveness of e-recruitment. The respondents of this study are Generation Y job seekers. They are a generation who are active in searching for jobs in the job market, computer savvy and have grown up with the Internet. The data is analyzed using the multiple regression analysis. The findings indicate that all the factors studied are contributing to the effectiveness of e-recruitment. This includes adaptability of hiring time cycle, the accessibility of information, the accessibility of internet, the usability of website, and cost effectiveness. Thus, organizations should pay greater attention on these factors in order to obtain the suitable pool of candidates.

(C) 2016 The Authors. Published by IASE. This is an open access article under the CC BY-NC-ND license (http://creativecommons.org/licenses/by-nc-nd/4.0/).
\end{abstract}

\section{Introduction}

Recruitment process is essential for an organization's success. This has been pointed out by Kaur (2015) who indicated that human resource and recruitment is a critical component of organizations' success since it generates human capital. Therefore, an effective recruitment assists in attracting talented and quality candidates.

Recruitment consists of practices and activities of an organization where potential employees are identified and attracted to apply for jobs (Breaugh and Starke, 2000). In other words, recruitment involves the process of seeking and attracting candidates for positions in an organisation (Dhamija, 2015). Anderson (2003) and McManus and Ferguson (2003) found Internet advancement has changed the recruitment process. According to Galanaki (2002) this method of recruitment is also referred as "Online Recruitment", "Internet Recruitment", and "Cyber-Recruiting". It is a method of advertising vacancies through the online method as well as to source information for job online through the Internet.

Online recruitment or e-recruitment is growing at a fast paste. A huge number of Fortune 500

\footnotetext{
* Corresponding Author.

Email Address: jayanty.kuppusamy@mmu.edu.my (J. Kuppusamy) https://doi.org/10.21833/ijaas.2016.12.014

2313-626X/C 2016 The Authors. Published by IASE.

This is an open access article under the CC BY-NC-ND license

(http://creativecommons.org/licenses/by-nc-nd/4.0/)
}

companies practices online recruiting (Feldman and Klass, 2002). From the perspective of job seekers over 52 million Americans use online job searches (Jansen et al., 2005). According to Cober and Brown (2006) more than 50 per cent of new employees were obtained from internet sources and this figure is expected to become higher. Girard and Fallery (2009) found in 2007 Monster France had more than 3 million CVs on their databases while over 36 million members were found in LinkedIn's social network in early 2009. Among the reasons stated for this growth is recruitment cost is cheaper when compared with traditional sources (Buckley et al., 2004) more choices to choose from since the number of resumes is much higher (Chapman and Webster, 2003) and it is being utilized as a main mode of applying for jobs (Chapman and Webster, 2003; Foster, 2003; Zusman and Landis, 2002).

Similarly, in the Malaysian context, Internet recruitment has also grown. A well-known Internet based job portal, (i.e., Jobstreet.com) which started in 1997 has grown to become the biggest online employment company in the region of Southeast Asia. It covers countries such as Malaysia, Singapore, Philippines, Indonesia and Vietnam. Currently, it has 3 million registered conditions, serving more than 230,000 corporate customers and has over 15 million job seekers (Jobstreet. com, 2016). In addition to that, numerous other online job portals have been formed and are operating in Malaysia.

Generation Y are those born between the year 1981 to 2000. They are regarded important because they are the current generation entering the 
workforce making them the highest number of recruitment source. A study by Society for Human Resource Management or SHRM in 2004 indicated them to be technologically savvy while Palfrey and Gasser (2008) referred this generation as the digital natives. In addition, the study by Coopers (2013) found this generation has natural aptitude for electronic forms of communications including e-mail and social media plat forms, Due to this, erecruitment will be highly applicable to them.

Therefore, it is critical to identify what are the factors that contribute to the effectiveness of erecruitment. The respondents of the study are job seekers whose consist of Generation Y. Through identifying and understanding these factors a more effective e-recruitment system can be introduced. Furthermore, due to the limited studies done in the Malaysian context such as usability of e-recruitment website (Musa et al., 2006), the pros and cons of Internet recruitment (Mohamed and Musa, 2007), adoption of Internet recruitment technology (Tong, 2009) and university student's perceptions toward Internet recruitment (Wendy et al., 2013) presents a motivation to conduct this research.

\section{Literature review}

E-recruitment is a recruiting process through Web-based tools such as on an organization's public Internet site or its intranet among others. According to Kim and O'Connor, (2009) e-recruitment includes searching for information about a job as well as the application process by a candidate while Allden and Harris (2013) define it as a process that discovers and recruits talented individuals from the Internet. E-recruitment growth had increased in mid-1990's when high qualified applicants were in demand (Lee, 2005). According to Kaur (2015) e-recruitment is the latest trend in the current competitive globalized era.

Effectiveness is defined as hiring the right person while Thomas and Ray (2000) suggested that the effectiveness is the ability to attract, to hire, and to develop talents. This study refers effectiveness as the measure of quality and goodness in using erecruitment. Vidot (2000) suggested that erecruitment can attract high quality candidates. Nevertheless, it is argued that e-recruitment should be applied together with other methods (Rosita and Nadianatra, 2006). This is because internet recruiting will not replace traditional practices of recruiting (Borck, 2000). Hogler et al. (1998) state that e-recruitment may increase the geographical scope of recruitment only but not the demographic scope. The reason being e-recruitment method might not be equally effective, in attracting job seekers from all levels in the demographic hierarchy within the societies. Indeed, for managerial level, executive and higher job level recruitment, traditional recruitment is more preferred by major organizations. This is because the need to have personal contact when applying jobs Arkin and
Crabb (1999). On the other hand, e-recruitment method is used to attract applicants for junior positions and the new graduates.

This study focuses on five factors namely the adaptability of hiring time cycle, accessibility of information, accessibility of Internet, usability of website, cost effectiveness. Helen and Sue (2008) states e-recruitment has a quick turnaround time (Cappelli, 2001; Galanaki, 2002; Zusman and Landis, 2002) compared to traditional recruitment process which has a longer hiring cycle time (Lee, 2005). Furthermore, position related information can be obtained more easily and at a greater speed at least "in theory" on e-recruitment (Cober et al., 2000). In addition, e-recruitment has personalized job agent tool which does a periodic search on job openings with predefined criteria and notifies candidates whenever a match is found between job availability and candidates' qualification (Lee, 2005). Jain and Goyal (2014) found majority of employees in their study of the Indian bank indicated quality of erecruitment system depends on many factors and one of them is quick response time.

Another key reason that encourages potential applicants to apply using e-recruitment would be the accessibility of information. According to Derous et al. (2004) information provision is regarded as a critical factor in terms of employment since it affects the values and expectations of the applicant. Cober et al. (2003) state that studies have shown those searching for job will seek for information on the organization and also the job itself. Marr (2007) found accessibility of information specifically on the job attributes, attracts quality applicants.

According to Singh and Narang (2008) Internet has become a preference in terms of job search. Their study shows that more than 40 per cent of their respondents who are university students visit job boards and websites of company two times a week while those surveying company website once a week was nearly $40 \%$. Williamson et al. (2003) posit that the expectations of individuals in terms of Internet technologies are the reason why they use online recruitment.

Lin and Stasinskaya (2002) report applicant assess company websites for recruitment process and it is stated to be different from other method since it is more vivid, interactive and dynamic (Cober et al., 2004). In other words, websites usability is regarded as a multifaceted construct and a highly developed human-computer interaction (Agarwal and Venkatesh, 2002; Nielsen, 2000). Cober et al. (2000) argue that in designing of company's website, consideration should be given to the ability to attract candidates, successfully engage them and ensure they apply for the position posted in the website. Therefore, there are certain issues that require specific attention such as organizational website's content and style (Cober et al., 2003), role of privacy perceptions and internet knowledge (Harris et al., 2003), website orientation and outcome expectancy (Williamson et al., 2003), perceived website usability due to its characteristics (Agarwal et al., 2000; 
Nielsen, 2000; Venkatesh and Davis, 1996) and ease of use (Agarwal and Venkatesh, 2002).

According to Borstorff et al. (2005), online recruiting sites are fast, convenient, and inexpensive. Online recruitment is found to cost less especially in terms of selection of condition and also lost in productivity (William and Klau, 1997) and CIPD, 1999). Perry (2002) states job seekers searching jobs online enjoy benefits such a quick, convenient, reliable and timely. In addition, it is an efficient way to reach recruiters who are employment professionals and organizations without the restrictions from a geographical aspect. Lee (2005) found that when application is submitted electronically, applicants have the ability to send their resume with all the necessary information and application for multiple jobs can be done at any time of the day.

Thus, it is important to identify which factors influence e-recruitment's effectiveness from the job seekers' perspective to better improve and enhance e-recruitment's effectiveness in the near future.

\section{Methodology}

The respondents are potential job seeks such as final year students from universities and colleges and also graduates seeking for jobs who are all otherwise known as Generation Y. This is because the target respondents are believed to or will apply jobs using the e-recruitment method. According to Borstorff et al. (2005), online recruitment is suitable for those with high education and those who are computer savvy. The development of the questionnaire is based on the review of literature. The questions used Likert scale ranging from 1Strongly disagree to 5 Strongly Agree. After the questions were tested for errors, they were sending for survey. The snowball sampling was used in order to reach a wider target of respondents. The researcher personally administered the questionnaire to known contacts. The contacts in turn also assisted in identifying suitable target respondents through their interrelationship. In addition, questionnaires were also distributed through the online survey. The total questionnaires distributed using online survey and personally administered were 350 .

\section{Results and discussions}

The total response collected was 241. All the questions were tested to be reliable and valid. The reliability value was all above 0.70 . Out of that around 201 were collected through personally administered questionnaire and 40 through the online survey method. The respondents are mainly from the age group of between 20-29 years of age (75.9\%), while those whose age is 19 and below is around $20.7 \%$. Those above 29 are around 3.3\%. Around $51.9 \%$ of the respondents are female. In terms of race distribution, majority of them are Chinese (67.6\%), followed by Malay (22.8\%), Indian $(8.7 \%)$ and others $(0.8 \%)$. Most of the respondents are pursuing education at degree level (65.1\%), followed by diploma $(26.1 \%)$, and postgraduate (5.4\%).

Next the correlation analysis was conducted to test the relationship between the factors (The Adaptability of Hiring Time Cycle, Accessibility of Information, Accessibility of Internet, Usability of Website, and Cost Effectiveness) and effectiveness of e-recruitment. The result is presented in Table 1 . The highest correlation value is for the accessibility of internet ( $r=0.617)$, followed by the accessibility of information ( $\mathrm{r}=0.583$ ), cost effectiveness ( $\mathrm{r}=0.577$ ) and adaptability of hiring time cycle ( $\mathrm{r}=0.565)$. The lowest value is the usability of website, $(r=0.540)$. All of the five independent variables have positive relationship with effectiveness of e-recruitment at 0.000 significance level. Therefore, this means that the adaptability of hiring time cycle, accessibility of information, accessibility of Internet, usability of website, cost effectiveness all have significant relationship with effectiveness of e-recruitment.

Table 1: Results of correlation analysis

\begin{tabular}{|c|c|c|}
\hline & $\mathrm{r}$ & Sig. \\
\hline The Adaptability of Hiring Time Cycle (HC) & $0.565^{* *}$ & 0.000 \\
\hline Accessibility of Information (IF) & $0.583^{* *}$ & 0.000 \\
\hline Accessibility of Internet (IN) & $0.617^{* *}$ & 0.000 \\
\hline Usability of Website (WS) & $0.540^{* *}$ & 0.000 \\
\hline Cost Effectiveness (CE) & $0.577^{* *}$ & 0.000 \\
\hline
\end{tabular}

Next, multiple regression analysis is done to identify the predictors of effectiveness of erecruitment. Table 2 presents the multiple regression analysis results. The $r$ square value is 0.523 which indicates that $52.3 \%$ of the variation within the dependent variable could be explainable by the variation in the five independent variables. Furthermore, the $\mathrm{F}$ value is 51.601 and the $\mathrm{p}$ value is $0.000(\mathrm{p}<0.05)$. Therefore, it means that the at least one of the independent variables predicts the dependent variable (Table 3).
The coefficient analysis result is presented in Table 3. The significant value showed that all of the factors have $p$ value of below 0.05 . This means all the factors are predictors. The highest beta value is for accessibility of internet $(B=0.297)$. This indicates that accessibility of Internet is the most significant influencing factor on E-recruitment's effectiveness. This is followed by usability of Website $(B=0.191)$, adaptability of hiring time cycle $(B=0.188)$, accessibility of Information $(B=0.136)$ and the lowest is for cost effectiveness $(B=0.154 ; p<0.05)$. 
Table 2 Multiple Regression Analysis

\begin{tabular}{|c|c|c|c|c|c|}
\hline R & R square & Adjusted R square & Std Error of the Estimate & F & Sig \\
\hline 0.723 & 0.523 & 0.513 & 0.45516 & 51.601 & 0.000 \\
\hline
\end{tabular}

Table 3: Coefficient Table

\begin{tabular}{|c|c|c|c|c|c|}
\hline & \multicolumn{2}{|c|}{ Unstd Coeff } & Std Coeff & $\mathrm{t}$ & Sig \\
\hline & B & Std Error & Beta & & \\
\hline Constant & 0.078 & 0.258 & & 0.304 & 0.761 \\
\hline $\mathrm{HC}$ & 0.188 & 0.067 & 0.175 & 2.795 & 0.006 \\
\hline IF & 0.136 & 0.068 & 0.132 & 1.984 & 0.048 \\
\hline IN & 0.297 & 0.065 & 0.279 & 4.551 & 0.000 \\
\hline WS & 0.191 & 0.054 & 0.196 & 3.524 & 0.001 \\
\hline $\mathrm{CE}$ & 0.154 & 0.078 & 0.124 & 1.980 & 0.049 \\
\hline
\end{tabular}

The purpose of the study is to identify the factors that contribute towards the effectiveness of erecruitment among Generation Y. They consist of final years students from universities and colleges as well as graduates searching for jobs. They are considered appropriate to provide the information since they are potential job seekers and will actively search for jobs, are more computer savvy and are well versed with the relevant technology. Therefore, they will be able to access the effectiveness of erecruitment and regarded suitable for this study.

Five factors were tested to identify which contributes to the effectiveness of e-recruitment and the finding reveals all the factors tested are contributors. Adaptability of hiring time cycle is important to job seekers since it meant shorter waiting time period in job application process and this is supported by Helen and Sue (2008). Therefore, both the organization and job recruitment portals should have an efficient system that processes information in a timely manner. This will encourage talented applicants to use and apply for jobs. Accessibility of information is also found to contribute to effectiveness of e-recruitment. This finding is supported by previous studies such as Cappelli (2001), Cober et al. (2000), Derous et al. (2004), Fountain (2005) Sylva and Mol (2009) and Williamson et al. (2003). Among the information they usually require are regarding the job (Cober, et al., 2003), the organizations and career opportunities, information about their corporate values and benefits (Lievens et al., 2002) among others. This is because job seekers need this information in order to apply for jobs (Fountain, 2005). Thus, organizations and job recruitment portals who want to attract a quality pool of candidates to recruit should decide and make available the relevant information in the erecruitment system.

Next, Internet accessibility is also influencing the effectiveness of e-recruitment. This is because erecruitment process relies on Internet accessibility. Only then job seekers are able to apply jobs using this method any time of the day (Lee, 2005). Another reason is because it cut across geographical constraints (Helen and Sue, 2008). Thus, a condition for e-recruitment effectiveness is the Internet accessibility. The government through their policies should provide additional measure to promote the growth of the Internet. This can be done by improving the network coverage and capacity to improve Internet accessibility and penetration. In addition, the Broadband speed should be increased so that all Internets related activities such as erecruitment would be more efficient. Malaysia is still lacking compared to other developed countries in terms of Internet speed.

Website is one source of e-recruitment, where candidates apply directly to the organization instead to a third party. Therefore, usability of website is of concern to job seekers and has an impact on the effectiveness of e-recruitment. Braddy et al. (2008) found when the navigation of a website is easy, the willingness to apply for jobs are higher, while the more usable a website is, the higher the potential to use that website again (Musa et al., 2006). Therefore, organizations and job recruitment portals should take the initiative on ensuring the e-recruitment website appeals to their target group. Recommendation by Zusman and Landis (2002) include high quality organizational website with pictures, colors, attractive, concise text and easy navigation. Having a web appeal provides good perceptions of the organization (Thompson et al., 2008). Otherwise, there will be negative perceptions on the Internet recruitment due to poor website usability (Gibson and Swift, 2011; Williamson et al., 2003). Finally, cost effectiveness is also found to contribute to the effectiveness of e-recruitment. The government and the service provide should look into measures to improve overall service. This would increase the efficiency and thus reduce the cost factor.

\section{Conclusion}

The study has been able to satisfy the objective set which was to identify factors contributing to the effectiveness of e-recruitment. The output derived from the study is able to add to the existing literature. With the advancement of Internet related technologies, the role of e-recruitment would become more important in the future years. From the employers or organization's perspective, the effectiveness of e-recruitment is essential to ensure they are able to search for human talents which 
would have impact on their sustainability. Therefore, there is a need to strategize on hiring cycle time, information accessibility and website usability. Using a multi diverse team comprising of experts in human capital, marketing and information technology would be a plus in creating an attractive erecruitment site. The government and the players in the telecommunication industry should play an active role through effective policies in improving the Internet coverage, capacity, speed and penetration. Thus, the on effectiveness of erecruitment can be improved.

The study's main limitation is the sample size. Future study should consider using a higher number of respondents. Furthermore, successful job seekers can be used as the sample. Organisations' viewpoint can also be an area of future study especially in terms of effectiveness and challenges faced. In addition, future study may consider an inclusion of additional variables to the existing ones studied here.

\section{References}

Agarwal R and Venkatesh V (2002). Assessing a firm's web presence: A heurisitic evaluation procedure for the measurement of usability. Information Systems Research, 13(2): 68-186.

Agarwal R, Sambamurthy V, and Stair R (2000). The evolving relationship between general and specific computer self-efficacy: An empirical assessment. Information Systems Research, 11(4): 418-430.

Allden N and Harris L (2013). Building a positive candidate experience: Towards a networked model of e-recruitment. Journal of Business Strategy, 34(5): 36-47.

Anderson N (2003). Applicant and recruiter reactions to new technology in selection: $A$ critical review and agenda for future research. International Journal of Selection and Assessment, 11(2-3): 121-136.

Arkin A and Crabb S (1999).Who's byting?. People Management, 5(2): 58-62.

Borck JR (2000). Recruiting systems control resume chaos. Infoworld, 22(20): 47-48.

Borstorff PC, Marker MB, and Bennett DS (2005). Online recruitment: Attitude and behaviors of job seekers. Journal of Strategic E-Commerce, 5(1): 123.

Braddy PW, Meade AW, and Kroustalis CM (2008). Online recruiting: The effects of organisational familiarity, website usability and website attractiveness on viewers' impressions of organisation. Computer in Human Behavior, 24(6): 2992-3001.

Breaugh JA and Starke M (2000). Research on employee recruitment: So many studies, so many remaining questions. Journal of Management, 26(3): 405-434.

Buckley P, Minette K, Joy D, and Michaels J (2004). The use of an automated employment recruiting and screening system for temporary professional employees: A case study. Human Resource Management, 43(2): 233-241.

Cappelli P (2001). Making the most of online recruiting. Harvard Business Review, 79(3): 139146.

Chapman DS and Webster J (2003). The use of technologies in the recruiting, screening, and selection processes for job candidates. International Journal of Selection and Assessment, 11(2-3): 113-120.

Cober RT and Brown D (2006). Direct employers association recruiting trends survey. Booz Allen Hamilton, Washington, USA.

Cober RT, Brown DJ, and Levy PE (2004). Form, content and function: an evaluative methodology for corporate employment websites. Human Resource Management, 43(2-3): 201-218.

Cober RT, Brown DJ, Blumental, AJ, Doverspike D, and Levy P (2000). The quest for the qualified job surfer: It's time the public sector catches the wave. Public Personnel Management, 29(4): 479496.

Cober RT, Brown DJ, Levy PE, Keeping LM, and Cober AB (2003). Organisational websites: Website content and style as determinants of organisational attraction. International Journal of Selection and Assessment, 11(2/3): 158-169.

Coopers P (2013). PwC's NextGen: A Global generational study, evolving talent strategy to match the new workforce reality Summary and compendium of findings. PWC, London, UK.

Derous E, Born M, and Witte DK (2004). How applicants want and expect to be treated: Applicants' selection treatment beliefs and the development of social process questionnaire on selection. International Journal of Selection and Assessment, 12(1/2): 99-119.

Dhamija P (2015). E-recruitment: A roadmap towards E-human resource management. Journal of Arts, Science and Commerce, 3(2): 33-39.

Feldman DC and Klaas BS (2002). Internet job hunting: a field study of applicant experiences with on-line recruiting. Human Resource Management, 41(2): 175-192.

Foster M (2003). Recruiting on the Web smart strategies for finding the perfect candidate. McGraw-Hill, New York, USA.

Fountain $C$ (2005). Finding a job in the Internet age. Social Forces, 83(3): 1235-1262. 
Galanaki E (2002). The decision to recruit online: a descriptive study. Career Development International, 7(4): 243-251.

Gibson P and Swift J (2011). E2c: Maximising electronic resources for cruise recruitment. Journal of Hospitality and Tourism Management, 18(1): 61-69.

Girard A and Fallery B (2009). E-recruitment: New practices, new issues. An exploratory study. In Boudarouk T and Ruel H (Eds.), Human Resource Information System: 39-48. Proceedings of the $3^{\text {rd }}$ International Workshop on Human Resource Information Systems, INSTICC Press, Milan, Italy.

Harris MM, Van Hoye G, and Lievens F (2003). Privacy and attitudes towards internet-based selection systems: a cross-cultural comparison. International Journal of Selection and Assessment, 11(2/3): 230-236.

Helen V and Sue W (2008). Advantages and disadvantages of internet recruitment: A UK study into employers' perceptions. International Review of Business Research Papers, 4(1): 364373.

Hogler RL, Henle C, and Bemus C (1998). Internet recruiting and employment discrimination: A legal perspective. Human Resource Management Review, 8(2): 149-164.

Jain A and Goyal A (2014). E-recruitment and Ehuman resource management challenges in the flat world: A case study of Indian banking industry (With special reference to ICICIBank, Jaipur). International Journal of Scientific and Research Publications, 4(1): 1-8.

Jansen B, Jansen K, and Spink A (2005). Using the web to look for work. Internet Research, 15(1): 49-66.

Kaur P (2015). E-recruitment: A conceptual study. International Journal of Applied Research, 1(8): 78-82.

Kim S and O'Connor J (2009). Assessing electronic recruitment implementation in state governments: Issues and challenges. Public Personnel Management, 38(1): 47-66.

Lee I (2005). The evolution of E-recruiting: A content analysis if fortune 100 career web sites. Journal of Electronic Commerce in Organizations, 3(3): 5768.

Lievens F, Dam KV, and Anderson N (2002). Recent trends and challenges in personnel selection. Personnel Review, 31(5): 580-601.

Lin L and Stasinskaya V (2002). Data warehouse management issues in online recruiting. Human Systems Management, 21(1): 1-8.

Marr ER (2007). E-Recruitment: The effectiveness of the Internet as a recruitment source. Ph.D Dissertation, School of Management, Faculty of
Business, Queensland University of Technology, Brisbane, Australia.

McManus MA and Ferguson MW (2003). Biodata, personality, and demographic differences of recruits from three sources. International Journal of Selection and Assessment, 1(2-3):175-183.

Mohamed OR and Musa N (2007). E- recruitment: pros vs. cons. Public Sector ICT Management Review, 1(1): 35-39.

Musa N, Junaini SN, and Bujang YR (2006). Improving usability of e-recruitment website: A preliminary study on Sarawak government website. Proceedings of Pacific Asia Conference on Information Systems (PACIS), Kuala Lumpur, 10: $507-515$.

Nielsen J (2000). Designing web usability: The practice of simplicity. New Riders Publishing, Indianapolis, USA.

Palfrey J and Gasser U (2008). Born digital: Understanding the first generation of digital natives. Basic Books, New York, USA.

Perry P (2002) Battle for the best: What works today in recruiting top talent?. Research-Technology Management, 4(2): 1-8.

Rosita MO and Nadianatra M (2006). E-recruitment practice: Pros and cons. Public Sector ICT Management Review, 1(1): 35-40.

Singh L and Narang L (2008). Behavioral revelation concerning E-recruitments. The IUP Journal of Organizational Behaviour, 7(4): 45-53.

Sylva H and Mol ST (2009). E-recruitment: A study into applicant perception of an online application system. International Journal of Selection and Assessment, 17(3): 311-323.

Thomas SL and Ray K (2000). Recruiting on the web: high-tech hiring. Business Horizons, 43(3): 43-57.

Thompson LF, Braddy PW, and Wuensch KL (2008). E-recruitment and the benefits of organisational web appeal. Computers in Human Behaviour, 24(5): 2384-2398.

Tong DYK (2009). A study of e-recruitment technology adoption in Malaysia. Industrial Management and Data Systems, 109(2): 281-300.

Venkatesh V and Davis FD (1996). A model of the antecedents of perceived ease of use: development and test. Decision Sciences, 27(3): 451-481.

Vidot J (2000). Online Recruitment: Taking the plunge. Available online at: http://www.gradlink.edu.au/grandlink/employe r/e_onlineartic.htm [Accessed 2011, April 12].

Wendy MYT, Tan SC, and Chong SC (2013). Factors influencing perceptions of university students towards internet recruitment. Asian Academy of Management Journal, 18(1): 123-142. 
William M and Klau B (1997). 10 Easy tips for recruiting online. Workforce, 76(8): 13-17.

Williamson IO, Lepak DP, and King J (2003). The effect of company recruitment web site orientation on individuals' perceptions of organizational attractiveness. Journal of Vocational Behavior, 63(2): 242-263.

Zusman RR and Landis RS (2002). Applicant preferences for web-based versus traditional job postings. Computers in Human Behavior, 18(3): 285-296. 